\title{
Fabrication of Biosensor for Selective Electrochemical Determination of Glycated Hemoglobin
}

\author{
Min $\mathrm{Li}^{1}$, Wenjie Zhao ${ }^{1}$, Linlin Tian ${ }^{1}$, Huafeng $\mathrm{Li}^{1}$ and Bo Fan ${ }^{2, *}$ \\ ${ }^{1}$ Department of Endocrinology, The Third Affiliated Hospital of Qiqihaer Medical University, 27 \\ Taishun Road, Qiqihaer, Heilongjiang, 161000, P.R. China \\ ${ }^{2}$ Department of Electrophysiology, The Third Affiliated Hospital of Qiqihaer Medical University, 27 \\ Taishun Road, Qiqihaer, Heilongjiang, 161000, P.R. China \\ E-mail: fanbo543@yeah.net
}

doi: $10.20964 / 2017.09 .09$

Received: 13 May 2017 / Accepted: 25 June 2017 / Published: 13 August 2017

The glucose level in diabetic patients should be detected without short-term fluctuations. Diabetes mellitus was used as a platform to investigate the glycated hemoglobin (HbA1c) level. HbA1c tops the list of main factors in discerning the concentration of the average plasma glucose during an extended period. In this study, a biosensor was fabricated based on a nitrogen-doped graphene/gold nanoparticle (AuNP)/fluorine-doped tin oxide (FTO) glass electrode immobilized with fructosyl amino-acid oxidase (FAO). This biosensor is highly sensitive and selective towards the determination of HbA1c. The limit of detection (LOD) is $1.70 \mu \mathrm{g} / \mathrm{mL}$, and the linear range is $10-65 \mu \mathrm{g} / \mathrm{mL}$.

Keywords: Glycated hemoglobin; Fructosyl amino-acid oxidase; Nitrogen-doped graphene; Electrochemical determination; AuNPs

\section{FULL TEXT}

(C) 2017 The Authors. Published by ESG (www.electrochemsci.org). This article is an open access article distributed under the terms and conditions of the Creative Commons Attribution license (http://creativecommons.org/licenses/by/4.0/). 